\title{
ONDINA: LA METÁFORA DEL CARNAVAL
}

\author{
Emilio Chinchilla Rodríguez
}

\begin{abstract}
RESUMEN
En este artículo se presenta una lectura del texto "Ondina" de Carmen Naranjo usando la Teoría de los Incipit, para descubrir rasgos carnavalescos. Mediante el análisis se puede observar que el cuento cumple con características del carnaval citadas por Bajtín, como lo grotesco, lo paródico, la óptica al revés, entre otros. En el pequeño relato se ve cómo el personaje homónimo puede ser visualizado como un carnaval.

Palabras clave: carnaval, Ondina, Carmen Naranjo, intertextualidad, incipit, grotesco.
\end{abstract}

\begin{abstract}
This article presents a reading of the text "Ondina", Carmen Naranjo using the Theory of Incipit to discover traits carnivals. Through the analysis it can be seen that the story meets features carnival Bajtin cited by, among others, as grotesque, parody, optics backwards. In the small story is the same name as the character can be viewed as a carnival.

Key words: carnival, Ondina, Carmen Naranjo, intertextuality, incipit, grotesque.
\end{abstract}

Empleando la Teoría de los Incipit, se pretende en este trabajo evidenciar los rasgos carnavalescos del texto "Ondina" presente en la colección de relatos homónima, con la que Carmen Naranjo ganó el Certamen Literario de Educa en 1983. Pues bien, teniendo eso presente comencemos por el comienzo, parafraseando a Amoretti ${ }^{1}$.

\section{Abordando el Incipit}

Es imposible iniciar el análisis de una obra sin adoptar una visión significante primeriza sobre la obra, dice Barthes (citado por Amoretti 1983: 145), ya sea temática, simbólica, o

Emilio Chinchilla Rodríguez. Licenciado en Ciencias de la Educación con énfasis en Docencia en la Enseñanza del Castellano y la Literatura. Profesor de español en el Colegio Daniel Oduber Quirós.

Correo electrónico: emiliochrod@costarricense.cr, emiliochrod@gmail.com

Recepción: 4- 2- 2008

Aceptación: 1- 3- 2008 
ideológica. Debido a ello, hay que acercarse a ese inicio, desentrañarlo y hallar una o más lecturas posibles. Para Chaverri (1986), este inicio debe darse con el título pues como afirma: "El título es el primer contacto del lector con un texto, es el nombre del texto, es el signo y por lo tanto es un meta-signo que ejerce sobre el lector su autoridad como programador de lectura..." (1983: 3). De esta forma, en el análisis que nos ocupa, se comenzará por el título.

Ondina es la palabra que nos ocupa. Veámosla primeramente de forma distanciada de su cotexto. Ondina viene del latín 'unda' que quiere decir ola, onda. Como palabra genérica, ondina nos refiere mitológicamente a las ninfas del agua, seres mágicos y hermosos, inmortales y con gran relación con la naturaleza. Tradicionalmente fueron conocidas como seres bondadosas protectoras de las aguas; no obstante, existen también relatos que ubican a una ondina como ser

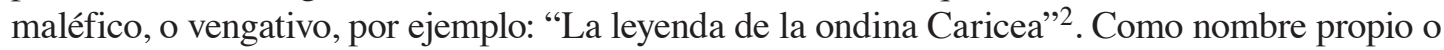
sustantivo, Ondina evoca también a un ser ansioso de amor que, aunque parece bueno, termina siendo malvado ${ }^{3}$. Con lo que hemos visto hasta acá, el signo Ondina es dual, permite encerrar dentro de sí lo bueno y lo malo a la vez, lo positivo y lo negativo. Hasta este momento, Ondina es una metáfora de la complejidad, de la articulación de los opuestos, aparentemente no llevaderos. Desde un inicio, este título lo podemos leer como carnavalesco, ¿por qué?

Bajtín (1998: 25) engloba con el nombre de realismo grotesco a las imágenes referentes a la cultura cómica popular de la Edad Media y el Renacimiento; en ellas, advierte él, se tiende a degradar, vulgarizar o corporizar, especialmente lo sublime. Pero esto no tiene un valor exclusivamente negativo, sino más bien positivo, pues al degradarse algo dentro del carnaval, se amortaja y se siembra, se da a luz algo superior, se le renace. Esto implica que la imagen grotesca como señala el autor es ambivalente, puesto que enuncia los dos polos de una idea. Así, el nombre Ondina se constituye en una imagen grotesca, ya que ondina nos refiere a esa ninfa, esa mujer-diosa unida a lo natural, inmortal revestida de perfección; y a la vez a ese ser maléfico, vengativo.

Prosigamos con el primer párrafo de la historia para descubrir, de acuerdo con Duchet, citado por Amoretti (1983: 145), las respuestas a ¿quién?, ¿dónde?, y ¿cuándo?, y otras más en las que nos interesa adentrarnos.

Cuando me invitaron para aquel lunes a las cinco de la tarde, a tomar un café informal, que no sabía lo que era, si café negro con pastel de limón o con pan casero o con café con sorbos de coñac espeso, todo lo pensé, todo, menos las sorpresa de alguien que me fue presentado en retazos: Ondina (Naranjo 1983: 9).

Claramente, el primer párrafo nos ubica acerca de la invitación que recibe el señor Vega, personaje principal y narrador, a tomar un café informal a una casa, invitación que a la postre culminará con el descubrimiento del personaje de Ondina. El primer verbo que aparece en el fragmento muestra que el convite está organizado por parte varias personas, que hasta el momento de finalizar este párrafo pasan por desconocidos para el lector. La oración es absolutamente impersonal. El día de la reunión es el lunes; no es casual que sea así, el lunes es la metáfora del comienzo, del arranque. Y, ¿qué es lo que inicia? Pues que justo ese día le será presentada Ondina. Notemos la clase de jornada a la que invitan al protagonista, a simple vista no tiene nada de extraordinario, el café representa el momento de reunión de familiar, de tertulia; ese café al que está convidado Vega, no obstante, no es como cualquier otro, pues este es informal. Lo informal implica cercanía entre los tratantes, lo cual hace ver que el personaje disfruta de un ligamen fuerte con quienes lo invitan o, que estos desean estrecharlo.

Es interesante cómo el narrador manifiesta de una forma metafórica su desconcierto sobre la cita: “...que no sabía lo que era, si café negro con pastel de limón o con pan casero 
o con café con sorbos de coñac espeso, todo lo pensé, todo...” (Naranjo 1983: 9). Aquí la posibilidad de la bebida y la comida se convierte en el augurio del motivo de la reunión. Las expectativas del narrador no eran nada comparables con la realidad, con esa enorme y poderosa realidad que sería Ondina.

En el cierre del primer párrafo, Ondina está presentada como ese elemento sorpresivo, ¿agradable o no para el protagonista?, ese es un asunto que se resolverá más adelante en la lectura. Al personaje de Ondina lo irá descubriendo el narrador por partes, "En retazos" dice en el texto propiamente; la palabra "retazos" hace clara mención a un pedazo de tela, de esta forma, podríamos leer que ese conocimiento o esa visión del ser la metaforiza el narrador como una prenda de vestir, una prenda que va hilando o tejiendo. ¿Qué característica tiene esa ropa? Es por supuesto sorpresiva, inesperada, surgida por lo que podemos ver del lugar más inimaginable posible. Desde aquí por supuesto, podríamos marcar una oposición entre Ondina y el lugar en el cual se desenvuelve.

Relacionemos ahora lo que habíamos hablado acerca del título y lo que hemos dicho sobre este primer párrafo. Notemos en primer lugar que en este incipit, desde el título al primer párrafo, el cierre y el arranque emplean el mismo vocablo: Ondina. Dicha cualidad hace que este incipit lo podamos catalogar como circular; el incipit inicia en Ondina y hasta lo que hemos analizado, culmina en Ondina. ¿Será acaso que la historia para el narrador inicia en Ondina y finaliza en ella?, ¿dónde se ubica el narrador en esta perspectiva?, ¿fuera o dentro de este círculo que constituye la aparente personalidad de Ondina?, son algunas preguntas que podríamos aventurarnos a hacer en este momento.

Habíamos indicado, al referirnos al título, que el nombre Ondina es de carácter ambivalente, pues muestra una configuración compleja y contradictoria, ya que Ondina, mitológicamente, ha sido conceptuada como una diosa bella y protectora y también como un ser maléfico. Podríamos interpretar en este punto que la sorpresa por ese ser llamado Ondina obedece quizás a esa ambivalencia, elemento que, como habíamos anotado, es carnavalesco.

Dice Bajtín refiriéndose al carnaval que

\begin{abstract}
Todos estos ritos y espectáculos organizados a la manera cómica, presentaban una diferencia notable, una diferencia de principio, podríamos decir, con las formal de culto y las ceremonias oficiales serias de la Iglesia o del Estado Feudal. Ofrecían una visión de mundo, del hombre y de las relaciones humanas totalmente diferente, deliberadamente no-oficial, un segundo mundo y una segunda vida a los hombres de la Edad Media... (1998: 11).
\end{abstract}

\title{
Además afirma que
}

(...) el carnaval era el triunfo de una especie de liberación transitoria, más allá de la órbita de la concepción dominante, la abolición provisional de las reglas jerárquicas, privilegios, reglas y tabúes. Se oponía a toda perpetuación, perfeccionamiento y reglamentación, apuntaba a un porvenir incompleto (1998: 15).

En sus palabras, el carnaval les da una oportunidad de utopía a las personas, un momento de liberación del mundo, una oportunidad de encontrarse con los otros, pues como dice Bajtín: "El individuo parecía dotado de una segunda vida que le permitía establecer nuevas relaciones, verdaderamente humanas con sus semejantes" (1998: 15). El carnaval es una segunda vida, ciertamente marginal, en la que se parodia, crítica o reflexiona sobre esa primera vida. Siguiendo este planteamiento, si Ondina, con lo que se lleva recorrido del texto, se considera carnavalesca, porque su nombre lo es, ¿qué encierra ella? ¿Acaso Ondina podría leerse como una segunda vida, un ser femenino utópico, liberador, que parodia esa realidad 
fastidiosa, con la que sí podría encontrarse el narrador, pero que se encuentra al margen que, al igual que el carnaval, solo puede descubrirse en pequeños estadios?

Antes de responder dichas cuestiones, avancemos más en el texto. En el segundo párrafo el protagonista reanuda la construcción de Ondina en partes, incluso hasta lo hiperboliza: "Ondina siempre me llegó con intuiciones de rompecabezas de cien mil piezas" (Naranjo 1989: 9). En ambos casos, por supuesto el conocimiento es ajeno al poder del protagonista, puesto que asegura: "se me fue presentando" y "me llegó". Claro, en este fragmento hay una gran diferencia con el final del primer párrafo. En el primero se habla unívocamente de la presentación "en partes" de Ondina, mientras que en el segundo se destaca la palabra intuición, vocablo que implica adelantarse a la razón y por ende, a los sentidos. La conformación de Ondina surgió en pequeñas piezas en la vida del protagonista antes de verla siquiera, como ratifica después: "Aun en época de inflación, realmente me agotan cifras tan altas. No sabía ni su nombre ni su estilo, pero la presentía en cada actitud, en cada frase" (Naranjo 1983: 9). Podemos advertir en las frases anteriores que la llegada de Ondina a la vida del protagonista no era algo del todo inesperado; presentía su llegada, asegura él, o, ¿más bien la ansiaba?

\section{Recorriendo el texto}

Continuemos con el desarrollo del texto para, al finalizar, propiciar el enlace con el incipit, como lo considera Amoretti siguiendo a Duchet (1983: 145). De esta forma aterrizaremos en la lectura concreta que se quiere hacer de esta obra, de acuerdo con los objetivos enunciados en el trabajo.

Posterior al párrafo recientemente indicado, el narrador inicia su relato previo al primer contacto con Ondina. Describe, en primera instancia, cómo fue su relación con los Brenes que, de acuerdo con el contexto de lectura, podemos relacionar con la invitación al café de la cual habló en principio. Afirma que esta vinculación fue siempre "lineal". Esta palabra pareciera referirse indirectamente a lo moral, puesto que podemos entender lineal, como en forma recta, es decir: manera correcta; esto se comprueba al leer lo que sigue:

\footnotetext{
Este tipo de relación se define por la cortesía, las buenas maneras, el formalismo significado y significante en los cumpleaños, la nochebuena y el feliz año nuevo. Nunca olvidé una tarjeta oportuna en cada ocasión y hasta envié flores el día del santo de la abuela (Naranjo 1983: 9).
}

Esta relación lineal entre los Brenes y el narrador es ciertamente ironizada con su distanciamiento cuando señala: "Los Brenes me mantuvieron cortésmente en el corredor, después de vencer el portón de entrada, los pinos del camino hacia la casa y el olor de las reinas de la noche..." (Naranjo 1983: 10). Este olor a reinas de la noche es muy significativo; lo metaforiza Carmen Naranjo caracterizándolo como "un preámbulo de sacristía", el olor es "un muy particular antes" de llegar a la casa de los Brenes. Recuérdese que la sacristía es el lugar donde el padre se prepara para salir a dar misa y donde se guardan los ornamentos de culto. Rastreando el significado de la figura de Naranjo, la podríamos visualizar de la siguiente forma: la casa de los Brenes, al contener la sacristía, podría ser una suerte de templo o iglesia, lo que nos evocaría religiosidad, una cierta rigidez, un ambiente un poco lúgubre y por supuesto misterioso.

La llegada del protagonista al hogar de los Brenes se da por el supuesto cortejo que este hace a Merceditas, hija de los Brenes, a quien define como linda y sensual, y le asigna una característica zoomórfica: "con su aire de coneja a punto de cría", con lo cual ubica a esta 
mujer en un énfasis reproductivo, no como un ideal amoroso. Aunque trata de conquistarla, él mismo admite que ella se aleja de sus pensamientos por una cierta mecanización que se advierte en su aspecto, como si fuese como la máquina que usa para escribir cartas y otros menesteres. Merceditas, de hecho, no es la mujer ansiada físicamente por el narrador, la considera demasiado hervida para su paladar, lo que, aplicado dentro del campo de la cocina, podría implicar que ella estaba pasada o quemada para él. Esto se comprueba cuando va al funeral de los abuelos de ella y al sentir sus senos en su pecho, siente más bien temor, espanto. Considera que esas partes no están hechas para él.

Por cada abuelo la abracé con ardor de consuelo y sentí sus grandes pechos enterrados en los botones de mi saco negro. No me excitaron, más bien me espantaron. Demasiado grandes para mis pequeñas manos (Naranjo 1983: 11).

Aparte de lo físico, la frialdad en su trato, su desprecio por lo carnal y su corrección moral, hacen que él se aburra. Así, él percibe que la sensualidad a ella le produce asco y cuando él intenta seducirla, Mercedes se resiste y más bien termina regañándolo.

El tibio cortejo de Merceditas no era una idea exclusivamente del señor Vega, narrador de la historia; lo supo cuando algunas veces la acompañó hasta su casa, allí pudo ver a padres y abuelos exageradamente felices, lo que lo hizo sospechar que estaban preparando una trampa para que él y ella, ambos solterones, se unieran.

El presentimiento sobre algo misterioso que envuelve a los Brenes se da justamente cuando presencia la felicidad hiperbolizada de estos, lo asegura diciendo: “...presentía más allá de las puertas una orgía de hornos calientes en que se fermenta el bronce y reluce la plata" (Naranjo 1983: 11). Este secreto encierra en la metáfora anterior una dimensión inimaginable de emoción, puesto que no se habla solo de orgía, lo que evoca un placer múltiple, de varios tipos, sino que es muy caliente, es decir, inconteniblemente pasional. El primer ligamen con este secreto inicia con el encuentro de un banquito diminuto ante las camelias, cuya utilidad para un ser normal cuestiona.

El señor Vega pasa a ser un "don nadie", figura retórica con la que se designa su ausencia de poder, que termina siendo de ser y que usa para caracterizar ser despedido por asuntos políticos. De tal forma, su ligamen con los Brenes deja de existir y el misterio queda en vilo. Esta lejanía pareciera implicar que a ambos personajes lo único que los une es el trabajo, porque ni Merceditas, ni Vega tienen el interés de ir más allá.

Lo anterior se rompe con el funeral de los abuelos, que propicia la famosa invitación al café informal, con la que el protagonista inicia su relato. Allí va darse su primer contacto con Ondina. El señor Vega no tarda en descubrir que los Brenes conocen la probabilidad de que a él lo nombren en un alto puesto político y la invitación, aparte de la curiosidad, tiene también como finalidad propiciar un acercamiento entre él y Merceditas. Esta intención desnuda por supuesto la visión ciertamente de interés que se tiene por Vega.

Cualquier consideración sobre el café informal que presencia el señor Vega empieza a verse obnubilada. Surgen dos nuevos aspectos misteriosos: el primero, una silla bajita con almohadón, que sin duda relaciona con el banquito visto del jardín; descarta en principio la sorpresa que dicho objeto le produce y piensa que es un recuerdo de infancia.

El segundo factor de misterio lo avasalla con una fuerza increíble. Se trata de la joven bellísima pintada en el cuadro central de la sala; pregunta su nombre, Ondina, le dicen. La hermana menor de Merceditas, le vuelven a comunicar. A partir de dicha reunión, aquella imagen se vuelve una obsesión perenne; trata de buscarla infructuosamente, incluso de 
conocerla mediante el horóscopo, sin resignación, pide su mano sin siquiera haber hablado con ella y le es negada sin oportunidad por el padre. Le escribe una carta que no recibirá respuesta y que retirará Merceditas.

Su oportunidad se dará únicamente cuando mueren los padres, justo en su vela. Allí, en la casa de los Brenes, conocerá a una enana diminuta, figura hiperbolizada por demás, en una escena totalmente sorpresiva; a esta enana después la descubrirá, para su gusto, como Ondina. Habrá vinculación entre ambos que tropezará con un coito fallido en los albores de la vela y que hará al señor Vega finalmente, por lo que se lee, tomar la decisión de casarse con Merceditas, lo que en efecto se da un mes después de la muerte de los padres.

Hasta aquí hemos hecho un repaso general de la historia y nos hemos detenido analizando brevemente algunos aspectos. Ahora es el momento de conjuntar el cotexto y el incipit y concretar nuestra propuesta analítica.

\section{Ondina: la mujer carnaval}

Habíamos acotado, al principiar el análisis de este texto, que el nombre Ondina evoca una ambivalencia, una dualidad ciertamente contradictoria: el mal y el bien unidos en un vocablo. Esta característica de la ambivalencia, de la contradicción, hace que la palabra Ondina pueda leerse como carnavalesca y ello puede tener muchas implicaciones en cuanto a la interpretación de la obra.

Ahora bien, al completar la lectura de la obra, al menos desde nuestra perspectiva, esa imagen de nombre carnavalesco que posee Ondina se va mostrando a través de las metáforas en ese ser que totalmente carnavalesco; desde esta postura, Ondina es un carnaval, y el texto homónimo también termina siéndolo. ¿Por qué afirmamos esto? Veamos.

Empecemos por el personaje que le da nombre al cuento. Ondina, tal como lo anuncia o lo evoca su nombre, es ambivalente. El narrador la conoce primeramente a través de la imagen pictórica de la sala de los Brenes y se obsesiona con ella. Después, descubre para su entera satisfacción, que la enana diminuta oculta en la casa es Ondina; ella es tanto la imagen de la mujer alta y esbelta como la de la enana diminuta. La primera es su parecer, el engaño que fabrica un pintor a petición de los Brenes para disfrazar una temida realidad; la segunda es su ser, la parte escondida. Su familia la esconde por miedo a que conozcan la aberración de lo real.

Ondina es grotesca. Con ello están de acuerdo Tisnado (2005), Jones (1999) y Martínez (1987). Es una mujer que presenta la fusión de dos cuerpos en uno, característica importante del cuerpo grotesco, según Bajtin. Dentro de la mente del protagonista, es la mujer alta y esbelta del cuadro, y a la vez, es la mujer enana. Ondina es grotesca porque se presenta tan cerca de la muerte como del nacimiento; porque, como afirma Naranjo a través de las palabras de Vega: ella tiene "rostro de vieja, cuerpo de niña"(1983: 16).

También Ondina es grotesca porque incluso, desde la imagen previa del cuadro que visualiza Vega, ella busca el coito y lo ve como un juego, durante sus sueños. Además, cuando la llega a conocer hay un notorio énfasis en la visión de sus órganos genitales, así como del coito como juego; igualmente vemos cómo un gato sarnoso le hace el sexo oral, o cómo abre la bragueta de Vega para jugar con su pene.

Ondina representa para Vega algo muy especial, único. Desde el inicio del texto queda clara la idea de que aquel personaje se encuentra en total oposición al mundo que la rodea; por ello, para Vega representa sorpresa, diversidad ante lo que tiene al frente que no es otra 
persona que Merceditas. Merceditas representa la vida normal, la tradicional; es una mujer con apariencia sensual, de pechos grandes, con normas inflexibles, que se visualiza más como madre que como mujer desde la óptica del narrador. Por otro lado se encuentra Ondina, quien es nada menos que la segunda vida, en otras palabras, el carnaval; Ondina es la posibilidad de la utopía, la de la liberación de las normas, la de poder encontrarse con otro ser humano. En Ondina, Vega encuentra lo sensual, el juego, el alejamiento de lo estricto, todo lo contrario que le provoca Mercedes; claro, Vega sabe que no puede aislarse en la vida del carnaval, pues debe vivir también una vida tradicional. En los últimos párrafos del texto se manifiesta la forma de conjuntar los dos modelos de vida: “...hasta que encontré la clave de la convivencia. (....)Y me decidí de manera profunda y clara. (...)Los esponsales se fijaron al mes del duelo. A la boda asistió Ondina, el gato se quedó en la casa” (Naranjo 1983: 17).

Podemos leer en las anteriores declaraciones de Vega, cómo a pesar de que contrae matrimonio con Merceditas (su vida tradicional), desea disfrutar también del carnaval (Ondina). El indicar que Ondina asiste a la boda no es un acto inocuo; se supone que como hermana debía asistir, aunque sus características físicas pudieran complicar dicho asunto. Sin embargo, el protagonista tiene el arrojo de decir que ella asistirá a la boda, lo que consideramos como una forma de decir que participará integralmente en su vida.

Queda más que demostrado, creemos, el porqué el personaje Ondina puede considerarse carnavalesco, o propiamente dicho, como un carnaval para el personaje de Vega. Ahora bien, la lectura del carnaval en esta obra no se puede ceñir solo a este personaje, sino que podemos ir más allá.

\section{Ondina: un texto carnavalesco}

Una cualidad del carnaval que surge con claridad en el texto es la óptica de al revés, es decir, el voltear las cosas de punto de vista (Bajtín 1998: 16); así por ejemplo, para Vega el ideal de belleza no es el mismo que el de los demás, de esta forma los pechos de Merceditas le repugnan. Estaba "demasiado hervida para mi paladar", asegura él. Su gusto por lo femenino va dar una vuelta de hoja a lo normal, de esta manera él se "deleitaba en las deformidades de Picasso".

Por otra parte, la ambivalencia surge con una fuerza expresiva sin igual; podemos vislumbrarla sobre todo en el instante de la vela. El rezo, momento íntimo, casi sagrado de una familia que, dentro del contexto católico implica un ruego para que el ser llegue con bien a Dios y este le perdone sus faltas, es contrastado demoledoramente con la imagen del juego sexual que entablan Ondina y Vega. Lo profano y lo sacro se unen ahí de una forma inesperada. De igual forma es ambivalente el instante cuando Vega presencia la escena de sexo oral zoomórfico entre Ondina y el gato, el protagonista admite sentir horror, pero a la vez confiesa estar abstraído por unos segundos: "Sentí horror por la escena, aunque me atrajo por largos segundos..." (Naranjo 1983: 16). Las imágenes analizadas anteriormente, aparte de contradictorias y ambivalentes, como ya se había establecido, son grotescas, pues muestran un aspecto considerado por la realidad como feo o privativo como los órganos genitales, la presencia del gato sarnoso y el coito.

Un elemento esencial del carnaval es la risa (Bajtín 1998: 17). Una risa que lo abarca todo y a todos. Una risa que degrada, que parodia. Esto lo podemos observar muy bien en el texto: el narrador elabora su historia con base en finos momentos de humor; los personajes pocas veces no aparecen riendo, sin embargo los hechos se van presentando de forma que nos 
vamos encontrando con sucesos cómicos. Así se vuelve graciosa la historia que cuenta Vega de cómo en más de una oportunidad trató de acostarse con Merceditas, y esta lo rechazó y terminó regañándolo, por lo que él tomaba la decisión de subirle el sueldo para dejarla tranquila y callada. Es también risible la ocasión en que, sin conocer a Ondina más que por el cuadro, pide su mano a don Jacinto. Por último, con respecto a la risa, es cómico además el final; aunque no manifiesta nada más que se casó con Merceditas y que Ondina fue a la boda, juguetonamente, con clara risa está manifestando que Ondina va estar presente en su vida, muy presente.

El texto como carnaval representa una posibilidad de juego, de liberación. Constituye una posibilidad de reflexión a la vez sobre el mundo y por qué no, de otras obras literarias. En el caso de Ondina esta tiene como intertexto al cuento de Rubén Darío llamado "El caso de la señorita Amelia”, relato que podríamos decir se deconstruye en él primero, ¿cómo?

El texto de Rubén Darío presenta una historia fantástica. En esta, un hombre llamado Doctor Z narra como era gran amigo de una familia en la que había tres hijas, las cuales eran bien bellas; dos eran ya adolescentes y la menor, Amelia, tenía apenas doce años. El Doctor Z, quien ya había cumplido más de treinta, prodigaba a las dos mayores sus miradas seductoras, palabras labradas y declaraciones. A la menor considerándola una niña, la trataba como tal, con un aparente desdén. No obstante, para él Amelia era su favorita, sus ojos le encantaban y gozaba estar más cerca de ella que de las otras dos. De hecho, cuando hubo de despedirse, a la única que besó fue a Amelia, de forma amistosa, casi paterna, en la frente, aunque con una confluencia inexplicable de sensaciones. El Doctor Z pasó veintitrés años sin ver a esta familia. Cuando regresó, se encontró en la casa de los Revall y descubrió cómo aquellas jóvenes a las que jugaba seducir eran ya adultas y no se habían casado y que Amelia, Amelia no había cambiado nada en estos veintitrés años. Seguía siendo físicamente una niña, ahora con treinta y cinco años.

Como podemos ver, Manuel Vega al igual que el Doctor Z frecuenta la casa de una mujer (en el caso del primero) o mujeres (el segundo) en procura de una conquista sentimental que demora porque no es de su total agrado. Merceditas está dividida en Luz y Josefina, mujeres a las que se han acercado por una relación casual, mujeres cercanas de edad y también coinciden en que son solteras. Ambos, Manuel y el Doctor Z, prefieren a la candidata menos usual, la que constituye una rareza. Amelia y Ondina son lo extraño, lo marginado, las que incluso andan en una edad parecida, los treinta y pico de años.

Ahora bien, ¿qué parodia "Ondina" con respecto a "El caso de la señorita Amelia"? Es fácil. En "Ondina", como texto carnavalesco se procede una liberación, un rompimiento de tabúes, que no se vislumbra en la obra de Darío. Así, Manuel no tiene temor en confesar sus pesadillas ardientes, fantasías sexuales que se le dan incluso despierto. El Doctor Z por su parte, disfraza la sexualidad que evoca la muchachita, la pasión, y no la confiesa abiertamente, pues es un acto pedófilo. Amelia, al pasar los veintitrés años sigue siendo una niña tanto física como vivencialmente, mientras que Ondina tiene el cuerpo de niña, puesto que es una enana, el rostro y la mente de adulta. Aunque Ondina es como una niña corporalmente, eso no le impide a Manuel desearla e intentar poseerla sexualmente, e incluso aventurarse a crear un cierto futuro junto a ella. El Doctor Z, cuando vuelve a presenciar a Amelia ya adulta, con cuerpo y espíritu de niña, la mira desconcertado. Ya no puede desearla o, al menos, no lo confiesa.

El texto de "Ondina", al ser carnavalesco, no solo parodia la literatura, también lo hace con la realidad. Podemos ver por ejemplo, como se crítica el hecho de que para algunas 
personas el figurar y el poder sean razones para emprender una relación. De esta forma, Manuel Vega es recibido en el jardín, luego en el corredor de la casa los Brenes cuando es jefe de Merceditas y no es recibido en la sala, sino cuando se sabe que recibirá un puesto muy importante. Cuando está fuera del poder, el personaje es marginado, está ubicado fuera del alcance de sus deseos.

Otro aspecto que pone en el tapete la obra es la exagerada importancia que se da al aspecto físico de las personas. Ondina es marginada porque es una figura ominosa, que por un problema físico no puede crecer lo normal; ella reúne las características de una niña y una adulta. Su familia la esconde, pero no solo se limita a ello, sino aún peor, le fabrica una identidad ficticia. Así la imagen del cuadro la disfraza físicamente con un cuerpo alto y esbelto que no tiene. Su padre miente a Manuel contándole que ha rechazado a mejores hombres que él, cuando probablemente nunca se ha acercado a uno antes. Ondina, como mujer que es, se ve recluida en un mundo que no la comprende, que la encarcela. Debe sobrevivir en medio de su soledad y a su soledad. El sexo se vuelve aparentemente su liberación, para la que el gato, el sarnoso gato, se vuelve su instrumento. Este animal le completa con sus lamidas, mamadas y succiones el mundo, casi se vuelve una parte de ella.

Relacionado también con el aspecto físico, podemos ver en la obra que el gusto por una clase de figura humana corpórea no es un hecho fijo por la sociedad; de esta forma, Manuel no es el típico hombre que encontraría completamente atractiva a Merceditas, sino que su espectro de belleza encuentra hermosa a Ondina, la verdadera.

Para ir cerrando, retomemos lo articulado hasta ahora. Podemos afirmar en primer lugar, que el personaje de Ondina es carnavalesco, ya que es ambivalente, dual, grotesca. Su nombre evoca dos posibilidades y su vida está enmarcada entre dos identidades la falsa y la verdadera. Su figura a los ojos de los Brenes es deforme, grotesca, lo que para Manuel implica Belleza. Ondina no es solo carnavalesca, sino que es el carnaval mismo. Representa para el señor Vega la posibilidad de una segunda vida, más alegre, más reflexiva, hasta más humana que la permitida Merceditas, quien terminará siendo su vida tradicional.

No solo Ondina es carnavalesca en la historia. El texto en sí también lo es. Podemos observar en este la óptica al revés manifestada, por ejemplo, en cómo el estándar de belleza para Manuel no es el mismo que el de los demás hombres. La ambivalencia es presentada juguetonamente así, en medio de una vela, surge el sexo: vida y muerte unidas en un acto. Las imágenes grotescas sorprenden: podemos ver, por ejemplo, a una enana (figura ya de por sí grotesca, sosteniendo sexo oral con un gato, y no cualquiera, sino sarnoso). La risa es sorprendente en este texto. No es burlista, ni sarcástica, sino curiosa. Eventos sorprendentes y las reacciones de los personajes, así como sus razonamientos nos llenan de momentos cómicos.

El texto se mueve como un carnaval pues es una parodia, una parodia que degrada con el fin de elaborar un constructo, una reflexión poderosa. Dilucidamos en el texto la presencia de un intertexto literario, el relato denominado "El caso de la señorita Amelia", del cual se degradan algunos aspectos, como la relación del Doctor Z y Amelia. Además, el texto parodia y cuestiona también asuntos sociales, como el valor otorgado al poder y al dinero, y la verdadera belleza femenina.

Mediante el lenguaje que leemos desde el incipit, empezando con el título, descubrimos en "Ondina" un juego carnavalesco, al que no solo asistimos, sino que participamos, pues en el carnaval no hay espectadores, solo actores. En este ejercicio de crítica literaria nos hemos leído a nosotros mismos, a nuestra sociedad y cultura. 


\section{Notas}

1. Por su artículo citado en la bibliografía "Comenzar por el comienzo o la Teoría de los Incipit".

\section{La venganza de la ondina Caricea (leyenda)}

En los tiempos antiguos de la invasión romana en la Península Ibérica, dos altos cargos militares del ejercito invasor, Caris y Antis, entraron con sus tropas en Asturias, trabando con los naturales de aquella región una gran resistencia y sangrienta batalla haciéndoles huir hacia el río Nalón. Caris, alejándose entonces de Antis, remontó con sus hombres el Narcea, hasta cerca de Hermo. Enamorado y prendido de aquel paisaje, el caudillo invasor sintió unos grandes deseos de caminar por aquellos parajes. Un día, mientras sus hombres descansaban, se marchó solitario por la senda que conduce al Lago Noceda. Distraído, paseando entre la fronda, distinguió cerca de él una bella figura de mujer, con abundante cabe1lo suelto que le caía más abajo de las caderas.

Se trataba de la xana Caricea, espíritu maligno de los lagos, arroyos, fuentes y manantiales, cuyo odio hacia quien profanase sus dominios le habían hecho concebir una cruel venganza contra Caris. Éste al verla tan hermosa, se le acercó con la intención de hacerla prisionera y agregarla al nutrido botín de guapas asturianas que llevaba.

Pero la maléfica-bella Caricea huyó de su lado, sin darle tiempo de articular palabra. Caris, cada vez sentía más pasión ante tan hermoso y enigmático personaje. Intentó seguirla, pero no logró alcanzarla. Llegaron así a la misma orilla del lago Noceda, la xana, Caricea jadeante, detuvo su particular carrera, estaba extenuada, totalmente fatigada. Caris contempló extasiado unos instantes, sus verdes y transparentes ojos, y sin poder contener más tiempo allí parado, se abalanzó a ella y la abrazó apasionadamente entre sus brazos. Caricea se dejó abrazar, pero no tardó en abandonar su papel pasivo, rodeo el cuerpo del romano con tal fuerza, que lo dejó sin respiración, totalmente asfixiado.

Cuando la xana comprobó que sus pulmones ya no funcionaban arrastró al infeliz romano hacia la orilla del lago y lo arrojó en él.

Sus hombres buscaron desesperadamente a Caris por aquellos andurriales; nadie pudo nunca más hallar el cuerpo del joven caudillo romano, sepultado para siempre en las aguas del Lago Nocedal.

Tomado de: http://www.aol2002.com/public/leearticulos.php?mostrar=2004/Num\%2014\%20-\%20Mayo/ La\%20Venganza\%20de\%201a\%20Ondina\%20Caricea

Se presentan aquí, otras dos historias encontradas sobre Ondina.

En la mitología germánica, Ondina era una ninfa del agua. Era muy hermosa y, como todas las ninfas, inmortal. La única amenaza para la felicidad eterna de las ninfas era enamorarse de un mortal y dar a luz al hijo fruto de la relación. Eso significaba la pérdida inmediata de la inmortalidad.

Ondina se enamoró de un audaz caballero (Sir Lawrence) y se casaron. Tras pronunciar los votos, Sir Lawrence dijo: "Que cada aliento que dé mientras estoy despierto sea mi compromiso de amor y fidelidad hacia ti”. Un año después del matrimonio, Ondina dio a luz al hijo de Lawrence. Desde ese momento, ella comenzó a envejecer. Mientras el atractivo físico de Ondina se iba desvaneciendo, Lawrence perdía el interés en su mujer.

Una tarde, mientras Ondina estaba caminando cerca de los establos, escuchó el ronquido familiar de su marido. Cuando entró al establo vio entonces a Sir Lawrence recostado en los brazos de otra mujer. Ondina despertó a su marido rápidamente, le señaló con el dedo y pronunció su maldición: "Me juraste fidelidad por cada aliento que dieras mientras estuvieras despierto y acepté tu promesa. Así sea. Mientras te mantengas despierto, podrás respirar, pero si alguna vez llegas a dormirte, ¡Te quedarás sin aliento y morirás!

\section{Mitología Escandinava}

Ondina era una Nixie, un tipo de ninfa acuática de la Europa central, ella era una princesa de su raza, pero al igual que el resto de las nixies carecía de alma. La única orma en la que una nixie podís conseguir una era casándose por amor con un mortal.

Se dio la casualidad de que Ondina se enamoró de un hombre, un príncipe. Y su amor se vio correspondido. Habló con el rey de las nixies, que vivía en un enorme palacio de cristal bajo un tranquilo lago en 
lo más profundo del bosque, para que le diese su bendición y pudiera marcharse con él y casarse. El rey la dio su bendición, pero con una única condición. Que si su amado la era infiel, tendría sería castigado con la muerte por ello. Ondina aceptó.

Ella y el príncipe se casaron. Y durante largo tiempo fueron felices. Pero con el paso de los años Ondina vio flaquear a su marido y notó que tonteaba con otras mujeres. Ella aún enamorada profundamente de él decidió abandonarlo para tratar de salvar su vida. Volvió al palacio y le dijo al rey que había abandonado al príncipe porque ya no lo deseaba.

El príncipe sin saber porque su amada se había marchado entristeció, pues realmente era a la única mujer a la que seguía amando y siempre la había sido fiel y se lo sería mientras ella viviese. Pero como pasaron los años y ella no volvió la dio por muerta y al cabo del tiempo se volvió a enamorar y se casó de nuevo. El rey de las nixies lo supo y reclamó que fuese castigado. Y era Ondina la que debía llevar a cabo el castigo.

Cuando el príncipe salió a pasear a la orilla del lago (pues el bosque se encontraba en sus dominios y su palacio estaba muy cercano a él) Ondina emergió de él y lo llamó. ël loco de amor se acercó a ella. Ambos se abrazaron, ella no quería llevar a cabo el castigo. Y lo besó profundamente y se sumergió en las aguas. Él murió ahogado en ls profundidades del lago en medio del pasional último beso de Ondina.

Tomado de: http:// nevertobenext.blogspot.com/2006/01/la-maldicin-de-ondina-en-medicina.html y http:// elparaisodelosanhelosperdidos.blogia.com/temas/mitologia-leyendas- Bibliografía etc....php

\section{Bibliografía}

Alvarado, Óscar. 2003. "Lo ominoso discursivo como una manifestación del ser en el cuento “Ondina”". Kañina. 27 (2): 9- 15.

Amoretti, María. 1983. "Comenzar por el comienzo o la Teoría de los Incipit". Revista de Filología y Lingüística. 9 (1): 145- 154.

1992. Diccionario de términos asociados en Teoría Literaria. San José: EUCR.

1996. "La intertextualidad: un ensayo metacrítico". Revista de Filología y Lingüística. 22 (2): 7- 14.

Araya, Seidy. 1991. "La enajenación de la mujer en los sectores medios: Los perros no ladraron de Carmen Naranjo”. Kañina. 15 (1-2): 55- 65.

Bajtín, Mijaíl. 1998. La cultura popular en la Edad Media y en el Renacimiento, versión de Julio Forcat y César Conroy. Madrid: Alianza Editorial.

Budd, Ruth. 1999. La obra innovativa de Carmen Naranjo: una literatura abierta al futuro. VIII Congreso de Filología, Lingüística y Literatura "Carmen Naranjo".

Chaverri, Amalia. 1986. Introducción a una titulogía de la novelística costarricense. Tesis para optar por el grado de Licenciada en Filología Española: Universidad de Costa Rica.

Darío, Rubén. 1995. "La señorita Amelia". Verónica y otros cuentos fantásticos. Madrid: Alianza Cien. 
Jones, Sonia y Óscar Alvarado. 1999. "Ondina la búsqueda en retazos o retazos de una búsqueda". VIII Congreso de Filología, Lingüística y Literatura "Carmen Naranjo".

Martínez, Luz. 1987. Carmen Naranjo y la narrativa femenina en Costa Rica. Disertación para optar por el grado de Doctora en Filosofía y Letras, Universidad de Puerto Rico. San José: Educa.

1991. "Trayectoria vital en la obra de Carmen Naranjo". En: Kañina. 15 (1-2): 47- 53.

Naranjo, Carmen. 1983. Ondina. San José: Educa.

Tisnado, Carmen. 2005. "El Cuerpo Femenino y el concepto de belleza en dos cuentos de Carmen Naranjo". Revista de Filología y Lingüística. 31 (2): 23- 33. 